\title{
Hard Times Made Harder: Struggling Caregivers and Child Neglect
}

WENDY A. WALSH

I n 2008, 267,000 children were removed from their homes as a result of a child maltreatment investigation. ${ }^{1}$ The majority (69 percent) experienced neglect. The close relationship between child neglect, poverty, and placement in out-of-home care has been a long-standing concern among child welfare professionals. Because of this concern, seven states bar the removal of children for poverty-related reasons like homelessness or a person's financial inability to meet a child's basic needs. ${ }^{2}$ Yet, inadequacy of family income continues to be a strong predictor of whether a child reported to child protective services (CPS) is placed in foster care. ${ }^{3}$

Analyzing data from a nationally representative sample of children with a report of child neglect, this study finds that children whose caregivers struggle with drug abuse, mental health problems, alcohol abuse, or struggle to pay for basic necessities were more likely to be placed in out-of-home

\section{Key Findings}

- Neglected children from households with caregivers who struggle with drug use were three times as likely to be placed in out-ofhome care than those without drug problems.

- Neglected children who lived with caregivers with mental health problems, alcohol problems, or who had trouble paying for basic necessities were about twice as likely to be placed in out-ofhome care.

- Neglected children in rural and urban America had the same probability of being placed in out-of-home care.

- There was no difference in poverty and where neglected children were placed (for example, kin care, foster care, or group home/other placement). care than families without such struggles, even after controlling for other risk factors. These findings echo other research that demonstrates the many challenges families face that have a report of child neglect. ${ }^{4}$ Their struggles suggest that intervention and prevention must not only integrate substance abuse and mental health services but also address the needs and effects of long-term poverty, such as apathy, loss of hope, and indifference. ${ }^{5}$

\section{Neglected Children from Poor Households Are More Likely to Be Placed in Out-of-Home Care}

Neglect is the most common type of child maltreatment and includes physical neglect or supervisory neglect. ${ }^{6} \mathrm{~A}$ larger proportion (39 percent) of children experiencing physical neglect than supervisory neglect ( 25 percent) live in households that struggle to pay for the basics. This makes sense because physical neglect means the failure to provide for a child's physical needs.

Children with a report of neglect from households struggling to pay for the basics were significantly more likely to be placed in out-of-home care than neglected children from nonpoor households (see Figure 1). Slightly more than one in five children (21 percent) from a poor household was placed in out-of-home care compared with only 8 percent of children from a nonpoor household. This was also true for children experiencing physical neglect and supervisory neglect. There was no difference by family income in where neglected children were placed. Overall, 46 percent of neglected children were placed in kin care, 46 percent were placed in foster care, and 8 percent were placed in group homes or other placement arrangements. 


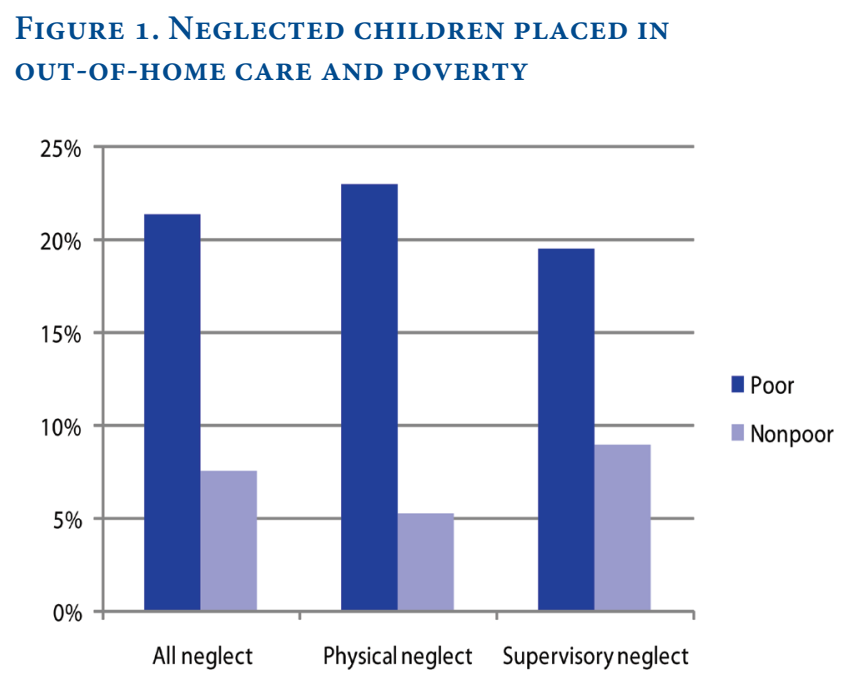

\section{Specific Risk Factors for Out-of-Home Placement for Neglected Children}

There are many other risks for placement besides poverty, including caregiver substance abuse, mental health problems, domestic violence, and a previous report of child maltreatment. To better understand the impact of poverty given these other possible predictors of placement, we conducted a multivariate logistic regression. This analysis accounts for these other possible risk factors and determines the probability of placement for one individual factor while controlling for other risk factors. This type of analysis is important because these risk factors tend to co-occur. Figure 2 shows the predicted probability of placement for each of these risk factors while controlling for other risks.

Caregiver struggles were important predictors of out-ofhome placement. Neglected children whose caregivers had drug problems had the highest probability of placement. Neglected children whose caregivers experienced other problems, such as mental health, alcohol, and lack of financial resources, also had an increased probability of placement.

Whether the child lived in rural or urban areas was not a significant predictor of placement, nor was child age, gender, type of neglect (physical or supervisory neglect), prior CPS report, or domestic violence.

\section{Definitions}

A caregiver is the person who has responsibility for parenting a child. Child neglect refers to the failure by the caregiver to provide needed age-appropriate care. ${ }^{7}$ It includes physical neglect or supervisory neglect. Physical neglect, or the failure to provide, refers to not meeting a child's physical needs, including food, clothing, shelter, medical, dental, mental health care, or hygiene. Supervisory neglect, or the failure to supervise, refers to not taking adequate precautions to ensure a child's safety, including supervision, environment, or substitute care. ${ }^{8}$

Out-of-home placement refers to placements two to six months after the close of the child neglect investigation. A poor household is defined as those where caseworkers responded that the family had trouble paying for basic necessities such as food, shelter, clothing, electricity, or heat. $^{9}$

We use the term rural to refer to all locations outside metropolitan areas. This includes both places adjacent and not adjacent to metropolitan places and includes codes four to eight on the county-level USDA classification categories. ${ }^{10}$ Urban refers to metropolitan places and includes codes one to three. For confidentiality reasons, respondents in the most rural places (USDA continuum code nine) were not included in the NSCAW sampling frame. Thus, our rural sample is not representative of those in the most remote places.

Figure 2. Predicted probability of Placement AMONG NEGLECTED CHILDREN, CONTROLLING FOR OTHER FACTORS

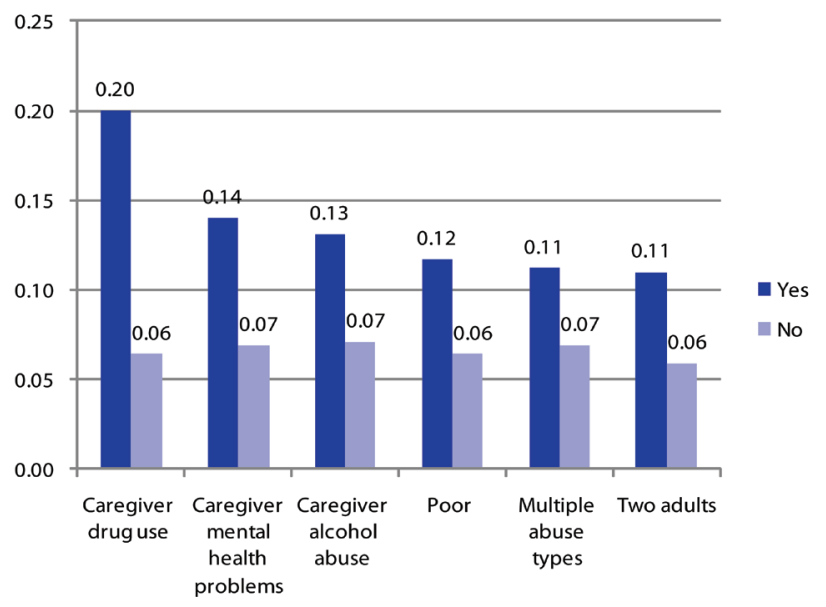

Note: Sample size is 2316, controlling for child's age, child's gender, type of neglect, prior CPS report, domestic violence, and rural versus urban 


\section{Data}

This brief relies on data from the National Survey of

Child and Adolescent Well-Being (NSCAW), a nationally

representative sample of children who had a maltreatment

report that resulted in a child welfare investigation. The

NSCAW survey included child maltreatment investiga-

tions between October 1999 and December 2000 for 5,501

children aged 0 to 16 years. Only children with a report of

neglect as the most serious type of abuse were included in

this analysis. NSCAW used a stratified two-stage cluster

sampling strategy that included ninety-two child protec-

tion agencies in thirty-six states. Additional information

on the NSCAW study design and sampling procedure

has been previously published. ${ }^{11}$ Baseline data included

face-to-face interviews with children, current caregivers,

and caseworkers. Statistics were computed using survey

weights to produce national estimates. All differences in

the text are statistically significant at $\mathrm{p}<.05$.

\section{Specific Risk Factors for Out-of- Home Placement for Neglected Poor Children}

We ran a second multivariate logistic regression selecting only children with a report of neglect and living in a poor household. This analysis allowed us to see what risk factors predict placement for this subgroup of children. This is important because chronic neglect is closely related to poverty. When we limited analyses to this group of children, we generally found similar predictors of placement for neglected children except that caregiver alcohol abuse did not predict placement among neglected poor children. Among this subgroup of neglected and poor children, caregiver drug abuse remained a strong predictor of placement. Experiencing multiple types of abuse and having a caregiver with mental health problems remained strong predictors of placement. Figure 3 shows the predicted probability of placement for each of these risk factors while controlling for other risks.

Whether the child lived in rural or urban areas was not a significant predictor of placement, nor was child age, gender, type of neglect (physical or supervisory neglect), prior CPS report, caregiver alcohol abuse, or domestic violence. These results show that, for both neglected children and neglected children from poor households, caregiver drug abuse and mental health problems are significant predictors of placement.

\section{Services to Prevent Neglect and Out-of-Home Placement Should Be Multifaceted}

Poverty is only one of many struggles that families face with a report of child neglect. This analysis found neglected children whose caregivers struggle with substance abuse and mental health problems are at significant risk for outof-home placement. Although many states have increased access to differential response systems, to family team meetings, and to flexible funding options, ${ }^{12}$ it appears that more needs to be done to ensure that all families receive the support they need in a timely manner.

The Fostering Connections to Success and Increasing Adoptions Act of 2008 created new resources and benefits to improve permanence and child well-being for children entering and exiting foster care. Having additional resources is a positive step. However, the 2004 federal child welfare budgetary policy spent about ten times more on out-ofhome placement than on family support services. ${ }^{13}$ This suggests that more could be done to better support families, such as integrating services for caregiver substance abuse and mental illness, before a child is placed out of the home. As others have suggested, more could be done to integrate these services with interventions designed to improve the long-term economic status of at-risk families. ${ }^{14}$

A recent evaluation of Ohio's Alternative Response Pilot Project is one successful example of addressing comprehensive family needs, many of which stemmed from poverty.

Figure 3. NegleCted CHILdREN PLACED IN OUT-OF-HOME CARE AND POVERTY

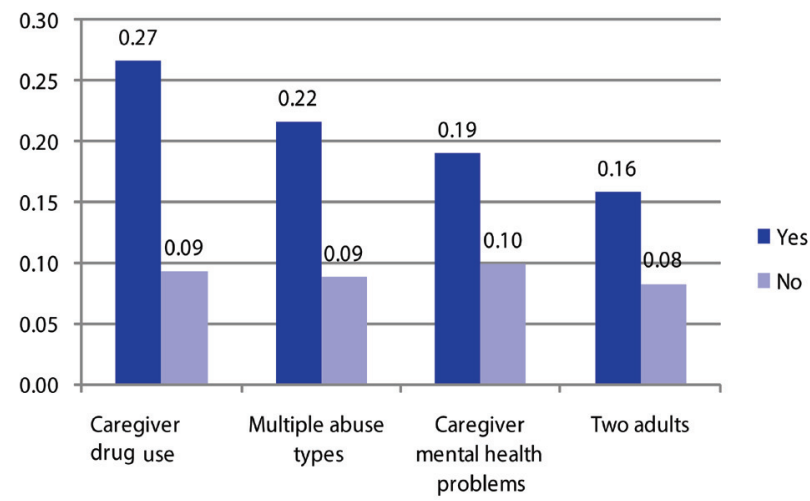

Note: Sample size is 1017, controlling for child's age, child's gender, type of neglect, prior CPS report, caregiver alcohol abuse, domestic violence, and rural versus urban 
This study randomly assigned families after a CPS report to an experimental group that received an alternative response family assessment or a control group that received a traditional response. ${ }^{15}$ The results indicated that providing poverty-related services (such as food, clothing, rent, help with obtaining appliances, transportation, and other financial help) and connecting families to counseling and mental health services reduced subsequent reporting of families for child abuse and neglect. Removals and outof-home placements of children also declined for families receiving the comprehensive alternative response services. The study concludes that, rather than focus resources on longer-term foster care, resources should focus more on prevention and support to families before a child is placed. Reform strategies could increase flexible use of federal funds, such as Title IV-E of the Social Security Act, to assist families early for family supports and preventive services to assist impoverished families at risk for a child being placed in out-of-home care. ${ }^{16}$

\section{E N D N O T E S}

1. U.S. Department of Health and Human Services, Administration on Children, Youth, and Families, "Child Maltreatment 2008” (Washington, DC: U.S. Government Printing Office, 2010).

2. C. Bullock, "Low-Income Parents Victimized by Child Protective Services," Journal of Gender, Social Policy and the Law, 11, 2 (2003): 1023-1053, retrieved August 23, 2010, from http://www.wcl.american.edu/journal/genderlaw/11/ bullock.pdf?rd-1.

3. R. Barth, J. Wildfire, and R. Green, "Placement into Foster Care and the Interplay of Urbanicity, Child Behavior Problems, and Poverty," American Journal of Orthopsychiatry, 76, 3 (2006): 358-366; B. Lery, "Neighborhood Structure and Foster Care Entry Risk: The Role of Spatial Scale in Defining Neighborhoods," Children and Youth Services Review, 31 (2009): 331-337; D. Lindsey, "Factors Affecting the Foster Care Placement Decisions: An Analysis of National Survey Data," American Journal of Orthopsychiatry, 61 (1991): 272-281.

4. D. D. DePanfilis and S. J. Zuravin, “The Effect of Services on the Recurrence of Child Maltreatment," Child Abuse \& Neglect, 26 (2002): 187-2051; N. Hindley, P. G. Ramchandani, and D. P. H. Jones, "Risk Factors for Recurrence of Maltreatment: A Systematic Review," Archives of Disease in Childhood, 91 (2006): 744-752.

5. D. Wilson, "Economic Interventions in Child Neglect," The Sounding Board, May 2010, retrieved November 1, 2010, from http://www.uwcita.org/Sounding\%20Board/5-10\%20 Economic\%20Interventions\%20in\%20Child\%20Neglect.pdf.
6. D. J. English and the LONGSCAN Investigations, "Modified Maltreatment Classification System (MMCS)" (1997), retrieved August 5, 2010, from http://www.iprc.unc. edu/longscan/pages/mmcs/LONGSCAN percent20MMCS percent20Coding.pdf.

7. U.S. Department of Health and Human Services, Administration on Children, Youth and Families, "Child Maltreatment 2008” (Washington, DC: U.S. Government Printing Office, 2010).

8. D. J. English and the LONGSCAN Investigations, "Modified Maltreatment Classification System (MMCS)” (1997), retrieved August 5, 2010, from http://www.iprc.unc.edu/ longscan/pages/mmcs/LONGSCAN\%20MMCS\%20Coding. pdf.

9. Six hundred and three cases had missing data on this question. For more information about this variable, see R. Barth, J. Wildfire, \& R. Green, "Placement into Foster Care and the Interplay of Urbanicity, Child Behavior Problems and Poverty," American Journal of Orthopsychiatry, 76, 3, (2006): 358-366.

10. "Measuring Rurality: Rural-Urban Continuum Codes" is available at http://www.ers.usda.gov/briefing/rurality/ ruralurbcon/.

11. NSCAW Research Group, "Methodological Lessons from the National Survey of Child and Adolescent Well-Being: The First Three Years of the USA's First National Probability Study of Children and Families Investigated for Abuse and Neglect," Children and Youth Services Review 24 (2002): 513-541.

12. J. Duva and S. Metzger, "Addressing Poverty as a Major Risk Factor in Child Neglect: Promising Policy and Practice," Protecting Children, 25, 1 (2010): 63-74.

13. C. Scarcella et al., “The Cost of Protecting Vulnerable Children: Understanding State Variation in Child Welfare Financing" (Washington, DC: Urban Institute, 2006), retrieved August 16, 2010, from http://www.urban.org/ UploadedPDF/311314_vulnerable_children.pdf.

14. D. Wilson, "Economic Interventions in Child Neglect.”

15. L. Loman, et al., "Ohio Alternative Response Evaluation Final Report” (St. Louis, MO: Institute of Applied Research, 2010), retrieved November 1, 2010, from http://www.iarstl. org/papers/OhioAREvaluation.pdf.

16. Duva and Metzger, "Addressing Poverty." 


\section{A B OUT THE AUTHOR}

Wendy A. Walsh is a research associate at the Carsey Institute and a research assistant professor of sociology at the Crimes Against Children Research Center at the University of New Hampshire (wendy.walsh@unh.edu).

\section{A C K N O W L E D G M E N T S}

I am grateful for feedback from Marybeth Mattingly, Mil Duncan, and Terri Rippett at the Carsey Institute; David Finkelhor and Lisa Jones at the Crimes Against Children Research Center at the University of New Hampshire; and Barbara Ray at Hired Pen for editorial assistance. 


\section{$\triangle$ UNIVERSITY of NEW HAMPSHIRE}

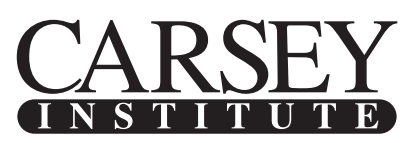

Building knowledge for families and communities

The Carsey Institute conducts policy research on vulnerable children, youth, and families and on sustainable community development. We give policy makers and practitioners timely, independent resources to effect change in their communities.

This work was supported by the Annie E. Casey Foundation, the W. K. Kellogg Foundation, and an anonymous donor.

Huddleston Hall

73 Main Street

Durham, NH 03824

$(603) 862-2821$

www.carseyinstitute.unh.edu 